\title{
p53-dependent and p53-independent anticancer effects of different histone deacetylase inhibitors
}

\author{
J Sonnemann ${ }^{\star 1,3}, \mathrm{C} \mathrm{Marx}^{2,3}, \mathrm{~S} \mathrm{Becker}^{1}$, S Wittig ${ }^{1}, \mathrm{C}$ D Palani ${ }^{1}$, O H Krämer ${ }^{2,4}$ and J F Beck ${ }^{1}$ \\ ${ }^{1}$ Department of Paediatric Haematology and Oncology, Jena University Hospital, Children's Clinic, Jena, Germany and \\ ${ }^{2}$ Department of Biochemistry, Center for Molecular Biomedicine, Institute for Biochemistry and Biophysics, Friedrich Schiller \\ University of Jena, Jena, Germany
}

Background: Histone deacetylase inhibitors (HDACi) are promising antineoplastic agents, but their precise mechanisms of actions are not well understood. In particular, the relevance of p53 for HDACi-induced effects has not been fully elucidated. We investigated the anticancer effects of four structurally distinct HDACi, vorinostat, entinostat, apicidin and valproic acid, using isogenic HCT-116 colon cancer cell lines differing in p53 status.

Methods: Effects were assessed by MTT assay, flow-cytometric analyses of propidium iodide uptake, mitochondrial depolarisation and cell-cycle distribution, as well as by gene expression profiling.

Results: Vorinostat was equally effective in p53 wild-type and null cells, whereas entinostat was less effective in p53 null cells. Histone deacetylase inhibitors treatment suppressed the expression of MDM2 and increased the abundance of p53. Combination treatments showed that vorinostat enhanced the cytotoxic activity of TRAIL and bortezomib, independent of the cellular p53 status. Investigations into the effects of an inhibitor of the sirtuin class of HDAC, tenovin-1, revealed that tenovin-1-mediated cell death hinged on p53.

Conclusion: These results demonstrate that vorinostat activates p53, but does not require p53 for inducing its anticancer action. Yet they also demonstrate that entinostat-induced cytotoxic effects partially depend on p53, indicating that different HDACi have a different requirement for $\mathrm{p} 53$.

In recent years, the importance of epigenetics in human cancer development has grown increasingly clear (Baylin and Jones, 2011). Epigenetic mechanisms, such as DNA methylation and histone acetylation, have thus become a focus of intense interest for the development of antineoplastic agents (Arrowsmith et al, 2012). Among the first fruits of this quest are drugs that target histone deacetylases (HDACs), the HDAC inhibitors (HDACi) (Spiegel et al, 2012). Two HDACi, vorinostat (also known as suberoylanilide hydroxamic acid, SAHA) and romidepsin (also known as FK228 and depsipeptide), have been approved by the US Food and Drug Administration as second-line treatments for cutaneous T-cell lymphoma, and several others, for example, panobinostat, belinostat and entinostat, are currently in phase II or III development for diverse oncological indications (Arrowsmith et al, 2012).

Histone deacetylase inhibitors block, with distinct specificities, a subset of the 18 isozymes belonging to the HDAC superfamily (Arrowsmith et al, 2012; Spiegel et al, 2012). The latter is divided into five phylogenetic classes: class I (HDAC1, 2, 3 and 8), IIa (HDAC4, 5, 7 and 9), IIb (HDAC6 and 10), III (sirtuins 1-7; SIRT1-7) and IV (HDAC11). The class III enzymes, the sirtuins, are biochemically unrelated to the enzymes of the other classes. They require $\mathrm{NAD}^{+}$instead of $\mathrm{Zn}^{2+}$ as a cofactor for their catalytic activity, and they are not affected by HDACi (of

\footnotetext{
*Correspondence: Dr J Sonnemann; E-mail: juergen.sonnemann@med.uni-jena.de

${ }^{3}$ These authors contributed equally to this work.

${ }^{4}$ Present address: Institute of Toxicology, University Medical Center Mainz, Mainz, Germany.
}

Revised 28 October 2013; accepted 30 October 2013; published online 26 November 2013

(C) 2014 Cancer Research UK. All rights reserved 0007 - 0920/14 
note, as in the majority of reports, the acronym 'HDACi' here refers only to the inhibitors of the $\mathrm{Zn}^{2+}$-dependent HDAC isozymes; sirtuin inhibitors are abbreviated as 'SIRTi'). HDACi elicit various antineoplastic effects: they stimulate differentiation, block proliferation, induce apoptosis, exert antiangiogenic and immune stimulatory activity, and, perhaps most importantly, augment the efficacy of other therapeutic regimens in tumour cells (Bots and Johnstone, 2009; Müller and Krämer, 2010; Spiegel et al, 2012). Histone deacetylase inhibitors function by increasing histone acetylation, but also by enhancing acetylation of nonhistone proteins including p53 (Buchwald et al, 2009).

The outcome of anticancer chemotherapy can depend on the tumour's p53 status (Soussi and Beroud, 2001). Tumour cells with mutated or deleted $p 53$ tend to be less responsive to several commonly used chemotherapeutic drugs, such as topoisomerase inhibitors, anthracyclines or alkylating agents (Lowe et al, 1993; Aas et al, 1996; O'Connor et al, 1997). Since p53 is the most frequently mutated gene in human malignancies, therapies that do not depend on functional p53 are in general clinically preferable. Hence, it is of considerable relevance to define a drug's requirement for functional p53 to exert its antitumoural activity.

To which extent the anticancer effects of HDACi are influenced by the tumour's $p 53$ status has not been unequivocally resolved. The majority of works addressing this issue point to a largely p53-independent action of HDACi (Vrana et al, 1999; Huang et al, 2000; Ruefli et al, 2001; Yu et al, 2002; Insinga et al, 2005; Sonnemann et al, 2006; Lindemann et al, 2007; Ellis et al, 2009). Other studies, however, suggest an essential role of p53 in the response of tumour cells to HDACi treatment (Henderson et al, 2003; Joseph et al, 2005; Kim et al, 2006; Condorelli et al, 2008; Hacker et al, 2011; Bajbouj et al, 2012; Meng et al, 2012). These inconsistent observations may in part be due to methodological differences, but they may also be due to the use of different HDACi or divergent HDACi-induced effects examined.

To shed more light on this issue, we employed variants of colon cancer HCT-116 cells differing only in their p53 status (wild type and null; henceforth referred to as p53 + and p53 - , respectively) (Bunz et al, 1998). In this isogenic pair, we assessed the effects of four HDACi belonging to four different structural classes, the hydroxamic acid vorinostat, the benzamide entinostat (also known as MS-275), the cyclic tetrapeptide apicidin and the shortchain fatty acid valproic acid (VPA). These HDACi have different selectivities: vorinostat inhibits $\mathrm{HDAC1}, 2,3,6$ and 8, entinostat inhibits HDAC1, 2 and 3, and apicidin and VPA inhibit HDAC1, 2, 3 and 8 (Bradner et al, 2010) (Supplementary Table 1). For comparison, we also assessed to which extent the $p 53$ status would alter the effects of two agents supposed to depend on p53, the sirtuin inhibitor tenovin-1 (Lain et al, 2008) and the topoisomerase II inhibitor etoposide (Lowe et al, 1993). We found that the single-agent responses to vorinostat, apicidin and VPA were largely independent of p53, while those to entinostat were partially and those to tenovin-1 were predominantly p53 dependent. We also found that vorinostat cooperated with various other agents to induce cell death in cancer cells irrespective of their p53 status.

\section{MATERIALS AND METHODS}

Reagents. Vorinostat, entinostat, apicidin, etoposide, z-VAD-fmk, pifithrin- $\alpha$ and caffeic acid phenethyl ester (CAPE) were purchased from Enzo Life Sciences (Lörrach, Germany). Valproic acid was purchased from Sigma (Deisenhofen, Germany). Tenovin-1 was purchased from Cayman Chemical (Ann Arbor, MI, USA). Bortezomib was purchased from LC Laboratories (Woburn, MA, USA). TRAIL was purchased from Peprotech (Hamburg,
Germany). Obatoclax was a gift from Dr C Wichmann (Munich, Germany).

Cell culture. HCT-116 p53 + and p53 - cells were a gift from Dr B Vogelstein (Baltimore, MD, USA). They were maintained in high-glucose DMEM with stable glutamine supplemented with $10 \%$ foetal calf serum, 100 units per ml penicillin G sodium and $100 \mu \mathrm{g} \mathrm{ml}^{-1}$ streptomycin sulphate (PAA, Cölbe, Germany). Cells were cultivated at $37^{\circ} \mathrm{C}$ in a humidified $5 \% \mathrm{CO}_{2}$ incubator and routinely passaged when $90 \%$ confluent. Cell viability was determined by the trypan blue exclusion test. Cells were regularly inspected to be free of mycoplasma with the PCR mycoplasma detection kit from Applichem (Darmstadt, Germany).

Treatment of cells. The cells were plated at 150000 cells per well in 6-well plates (all assays except MTT assay) or 30000 cells per well in 48-well plates (MTT assay) and treated with HDACi, tenovin- 1 or etoposide for $24 \mathrm{~h}$ (caspase- 3 assay, quantitative PCR and immunoblotting) or $48 \mathrm{~h}$ (flow-cytometric analyses and MTT assay). In the respective experiments, cells were pretreated with $z$-VAD-fmk, pifithrin- $\alpha$, CAPE or obatoclax for $1 \mathrm{~h}$. In the experiments with bortezomib and TRAIL, cells were pretreated with vorinostat for $4 \mathrm{~h}$ and then exposed to bortezomib or TRAIL for additional $48 \mathrm{~h}$.

Flow-cytometric analysis of cell death and mitochondrial transmembrane potential $(\Delta \psi \mathbf{m})$. Cell death was assessed by determining the integrity of the cell membrane by flow-cytometric analysis of propidium iodide (PI) uptake. After harvesting, cells were incubated for $5 \mathrm{~min}$ in $2 \mu \mathrm{g} \mathrm{ml}{ }^{-1} \mathrm{PI}$ in PBS at $4{ }^{\circ} \mathrm{C}$ in the dark. $\Delta \psi_{\mathrm{m}}$ was assessed by determining the accumulation of $3,3^{\prime}$-dihexyloxacarbocyanine iodide $\left[\mathrm{DiOC}_{6}(3)\right]$ (Molecular Probes, Eugene, OR, USA) in the mitochondrial matrix. Before harvesting, cells were incubated with $50 \mathrm{~nm} \operatorname{DiOC}_{6}(3)$ at $37^{\circ} \mathrm{C}$ for $30 \mathrm{~min}$. In both read-outs, 10000 cells were analysed in each sample on a BD FACSCanto II (Becton Dickinson, Heidelberg, Germany); data were gated to exclude debris.

MTT assay. At the end of the treatment periods, MTT reagent was added to a final concentration of $0.5 \mathrm{mg} \mathrm{ml}^{-1}$. After incubation at $37^{\circ} \mathrm{C}$ for additional $2 \mathrm{~h}$, the supernatant was removed and the water-insoluble product formazan was dissolved in 2-propanol. Formazan staining was determined by measuring the absorbance at $596 \mathrm{~nm}$ using a BMG Labtech FLUOstar Optima plate reader (BMG Labtech, Ortenberg, Germany).

Caspase-3 activity. Caspase-3 activity was measured using the fluorogenic substrate Ac-DEVD-AMC (Bachem, Weil am Rhein, Germany). After harvesting, cells were lysed in $10 \mathrm{~mm}$ Tris- $\mathrm{HCl}$, $10 \mathrm{~mm} \mathrm{NaH}_{2} \mathrm{PO}_{4} / \mathrm{NaHPO}_{4}$ (pH 7.5), $130 \mathrm{~mm} \mathrm{NaCl}, 1 \%$ Triton X-100 and $10 \mathrm{~mm} \mathrm{Na}_{4} \mathrm{P}_{2} \mathrm{O}_{7}$ and then incubated with $20 \mathrm{~mm}$ Hepes ( $\mathrm{pH} 7.5$ ), $10 \%$ glycerol, $2 \mathrm{~mm}$ DTT and $25 \mu \mathrm{g} \mathrm{ml}^{-1}$ Ac-DEVD-AMC at $37^{\circ} \mathrm{C}$ for $2 \mathrm{~h}$. The release of AMC was analysed on a BMG Labtech FLUOstar Omega (BMG Labtech) using an excitation/emission wavelength of $355 / 460 \mathrm{~nm}$. Relative caspase-3 activities were calculated as a ratio of emission of treated cells to untreated cells.

Flow-cytometric analysis of DNA content. To measure DNA content, ethanol-fixed cells were analysed for PI incorporation into DNA. After harvesting, cells were washed twice with PBS and fixed in $70 \%$ ethanol at $-20^{\circ} \mathrm{C}$ overnight. After centrifugation, cells were resuspended in PBS containing $1 \%$ glucose, $50 \mu \mathrm{g} \mathrm{ml}^{-1}$ RNase A (Roche, Mannheim, Germany) and $50 \mu \mathrm{g} \mathrm{ml}^{-1}$ PI and incubated in the dark at room temperature for $30 \mathrm{~min}$. Flow-cytometric analysis was performed on the FACSCanto II. In all, 20000 cells were analysed in each sample; data were gated to exclude debris. The different cell-cycle phases were quantified using the FACSDiva (Becton Dickinson) software. 
Quantitative real-time RT-PCR. Total RNA was isolated using the Peqgold Total RNA Kit including DNase digestion (Peqlab, Erlangen, Germany). RNA was transcribed into cDNA using Omniscript (Qiagen, Hilden, Germany). Quantitative PCR for p53, MDM2, MDM4 and p21 was performed using the Applied Biosystems (Darmstadt, Germany) 7900HT Real-Time PCR system. Expression levels were normalised to $\beta$-2-microglobulin. Reactions were done in duplicate using Applied Biosystems Gene Expression Assays (p53: Hs01034249_m1; MDM2: Hs99999008_m1; MDM4: Hs00159092_m1; p21: Hs00355782_m1; $\quad \beta$-2-microglobulin: Hs00187842_m1) and Universal PCR Master Mix. All procedures were performed according to the manufacturers' protocols. The relative gene expressions were calculated by the $2^{(-\Delta \Delta \mathrm{Ct})}$ method.

Immunoblotting. After harvesting by scraping, cells were resuspended in $50 \mathrm{~mm}$ Tris- $\mathrm{HCl}(\mathrm{pH} 8.0), 150 \mathrm{~mm} \mathrm{NaCl}, 1 \mathrm{~mm}$ EDTA, 1\% NP-40, 1\% sodium deoxycholate and 0.1\% SDS supplemented with a protease inhibitor cocktail and $0.5 \mathrm{~mm}$ PMSF, $0.1 \% \mathrm{NaF}, 1 \mathrm{~mm} \mathrm{Na}_{3} \mathrm{VO}_{4}, 20 \mathrm{~mm}$ glycerophosphate, $0.5 \mu \mathrm{M}$ trichostatin A and $10 \mathrm{~mm}$ nicotinamide followed by brief sonification. In all, 10-20 $\mu \mathrm{g}$ of total cellular protein per lane was separated by standard SDS-PAGE on $13 \%$ gels and electrophoretically transferred onto PVDF membrane. After blocking in $100 \mathrm{~mm}$ Tris- $\mathrm{HCl} \quad(\mathrm{pH} \quad 8.0), \quad 450 \mathrm{~mm} \mathrm{NaCl}, 5 \%$ dry milk and $0.05 \%$ Tween-20, proteins were immunodetected using antibodies against p53 (dilution $1: 50000)$, BCL2 (1:2500), MCL1 (1:5000), p53-inducible gene 3 (PIG3; $1: 5000)$, p21 (1:1000), BAX (1:1000) (Santa Cruz Biotechnology, Heidelberg, Germany), acetylated (K382) p53 (1:1000; Cell Signaling Technology, Danvers, MA, USA), MDM2 (1:1000; Calbiochem, Darmstadt, Germany), cleaved PARP-1 (1:5000; BD Pharmingen, Heidelberg, Germany) and acetylated histone H4 (1:10000; Upstate Biotechnology, Lake Placid, NY, USA). Equal loading of protein was verified by using either anti-HSP90 $(1: 10000)$ or anti- $\beta$-actin (1:50 000) antibodies (Santa Cruz Biotechnology). Peroxidaseconjugated anti-mouse or anti-rabbit IgG (1:5000; Pierce, Rockford, IL, USA) was used as secondary antibodies followed by detection of specific signals using SuperSignal West Pico Chemiluminescent Substrate (Pierce). Densitometric quantification
A
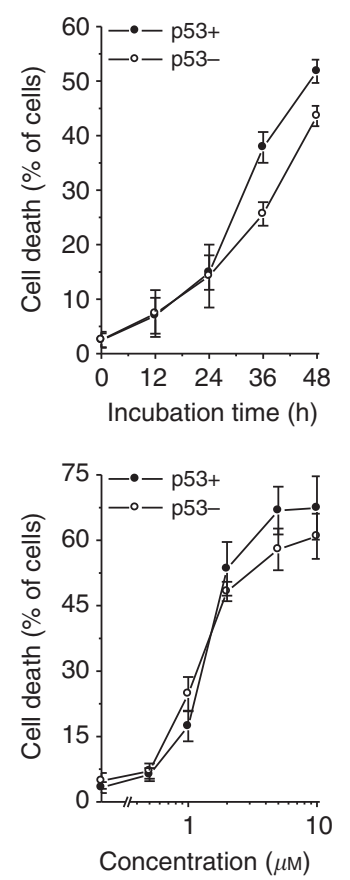

Entinostat
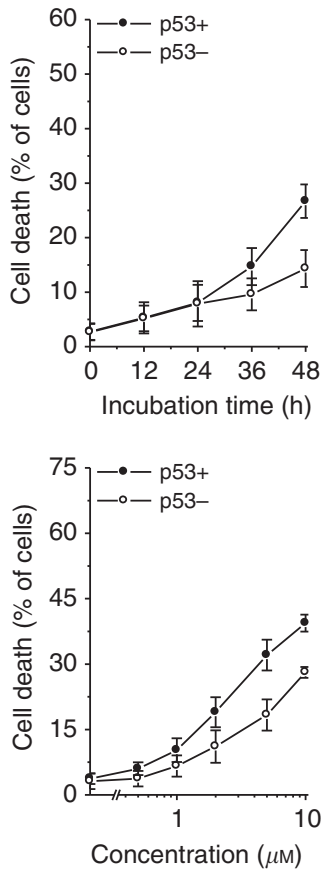

Apicidin
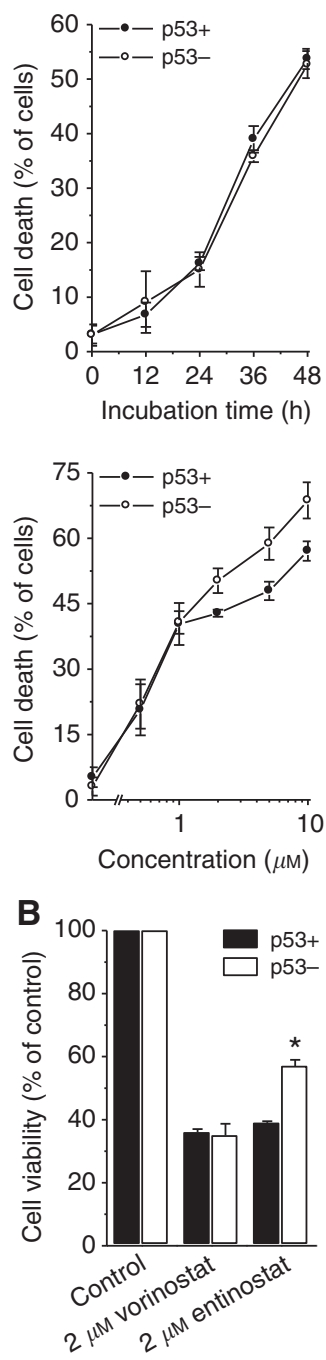

Valproic acid
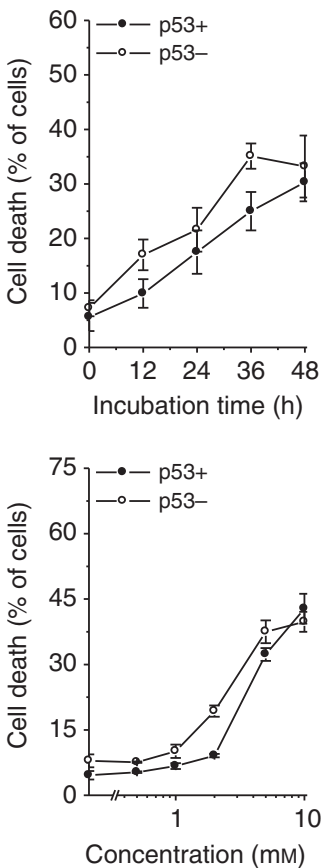

Etoposide
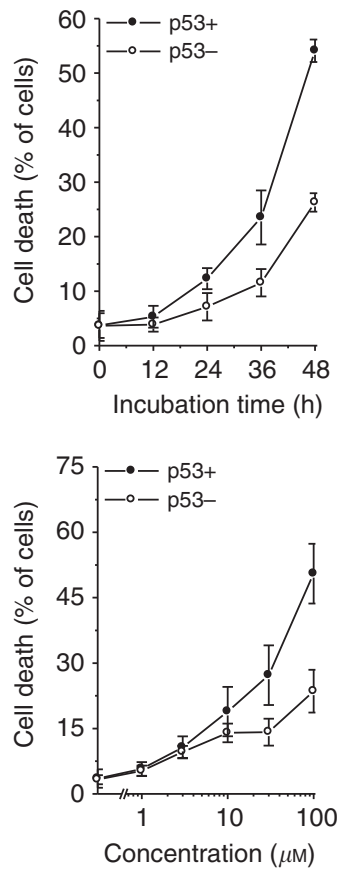

Figure 1. Antineoplastic effects of HDACi in HCT-116 p53 + and p53 - cells. Cells were exposed to HDACi or etoposide for $24 \mathrm{~h}(\mathrm{E})$ or $48 \mathrm{~h}$ $(\mathbf{A}-\mathbf{D}, \mathbf{F})$; in the time-course experiments (A, C), cells were exposed to $5 \mu \mathrm{m}$ of vorinostat, entinostat and apicidin, $5 \mathrm{~mm}$ VPA or $100 \mu \mathrm{M}$ etoposide. z-VAD-fmk was applied $1 \mathrm{~h}$ before treatment with $\mathrm{HDACi}(\mathbf{D}, \mathbf{F})$. (A, D) Cell death was determined by flow-cytometric analysis of PI uptake. (B) Cell viability was determined by MTT assay. (C, D) $\Delta \psi_{m}$ was determined by flow-cytometric analysis of DiOC 6 (3) staining. (E) Caspase-3 activity was determined using the fluorogenic substrate Ac-DEVD-AMC, relative caspase-3 activities are the ratio of treated cells to untreated cells. (F) Cell-cycle profiles were determined by flow cytometry. Means \pm s.e.m. of each three separate measurements are shown. 

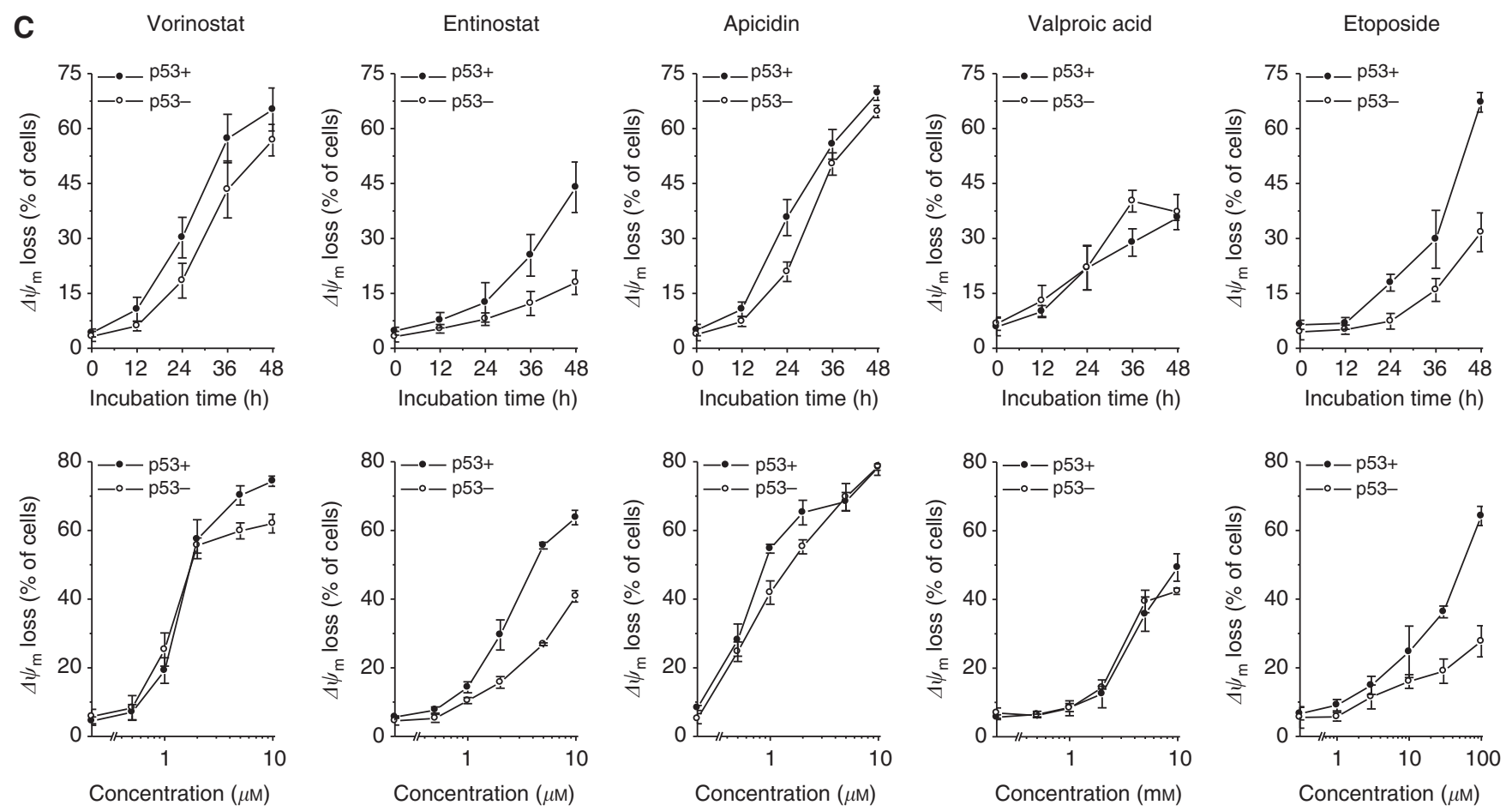
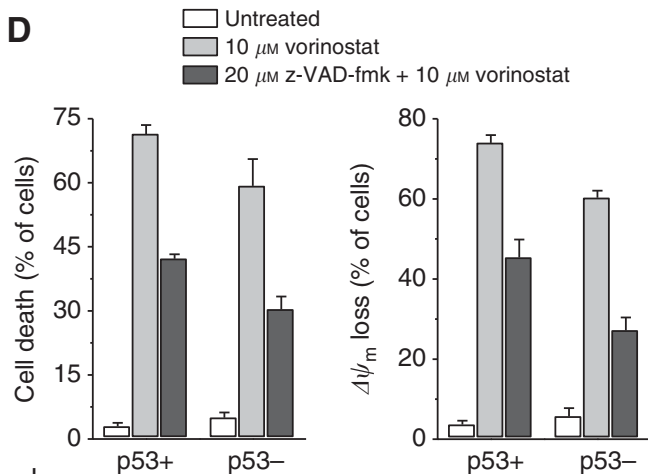

Figure 1. Continued.

of MCL1 normalised to HSP90 band intensities was done with ImageJ 1.47 (National Institutes of Health, Bethesda, MD, USA).

Statistical analysis. Statistical significance of differences between experimental groups was determined using two-tailed Student's $t$ test $\left({ }^{\star} P<0.05,{ }^{*} P<0.01\right)$.

\section{RESULTS}

Antitumour effects of HDACi on HCT-116 p53+ and p53 - cells. To investigate the effects induced by the four HDACi vorinostat, entinostat, apicidin and VPA in comparison with the cytostatic drug etoposide in HCT-116 p53 + and p53 - colon cancer cells, we first determined cell death by flow-cytometric analysis of PI uptake. Throughout the figures, p53 + cells are depicted by closed symbols and p53 - cells by open symbols. We assessed whether these compounds time and dose dependently affected the tumour cells. Figure 1A shows that all agents elicited cell death in a time- and dose-dependent manner in both p53+ and p53 - cells. However, the agents differed in their efficacy regarding the cells' $p 53$ status: the extent of vorinostat-, apicidinand VPA-induced cell death was practically independent of p53, whereas entinostat and etoposide were less effective in p53 - cells. While we had expected etoposide to act in a p53-dependent

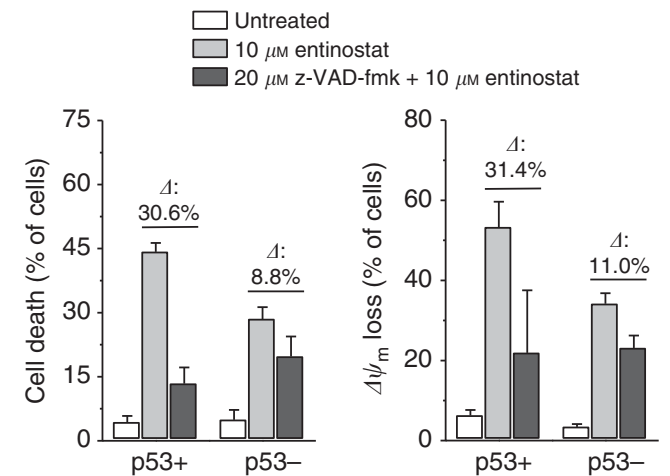

manner (Lowe et al, 1993), we were surprised to discover the difference between the HDACi. Thus, to verify these data, we compared the effects of vorinostat and entinostat on cell viability by MTT assay. As presented in Figure 1B, the results of the MTT assay reflect those of the PI uptake measurements: vorinostat was as effective in p53 - cells as in p53 + cells, whereas entinostat had a lesser effect on the viability of p53 - cells. To further corroborate these data, we studied the action of the five drugs on $\Delta \psi_{\mathrm{m}}$ by flowcytometric analysis of $\mathrm{DiOC}_{6}(3)$ staining. In all cases, the results matched those of the other assays: $\Delta \psi_{\mathrm{m}}$ dissipation induced by vorinostat, apicidin and VPA did not depend on p53, whilst entinostat and etoposide provoked a smaller decay of $\Delta \psi_{\mathrm{m}}$ in p53 - cells (Figure 1C).

Like other antineoplastic agents, HDACi are supposed to trigger cell death through the induction of apoptosis (Spiegel et al, 2012). Because p53 has a key function in the apoptotic response (Vousden and Prives, 2009), we investigated its contribution to HDACievoked apoptosis. To begin with, we determined the effect of $\mathrm{z}$-VAD-fmk on PI uptake and $\mathrm{DiOC}_{6}(3)$ staining analyses. $\mathrm{z}$-VAD-fmk is a broad-spectrum caspase inhibitor that serves to distinguish caspase-dependent from caspase-independent cell death (Chipuk and Green, 2005). Figure 1D shows that $\mathrm{z}$-VAD-fmk had divergent impact on the action of vorinostat and entinostat: it diminished vorinostat-induced cell death and $\Delta \psi_{\mathrm{m}}$ loss to roughly the same extent in p53 + and p53- cells, 

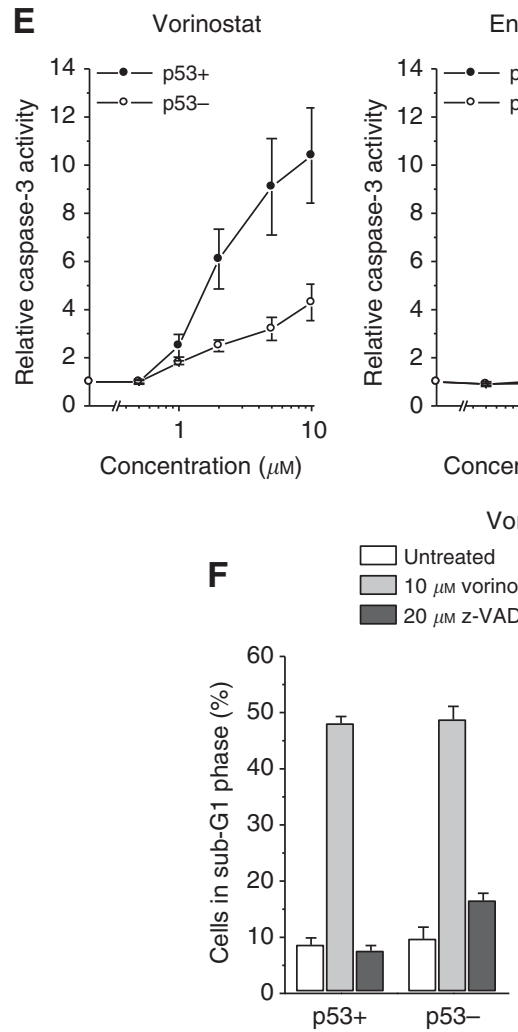

Vorinostat
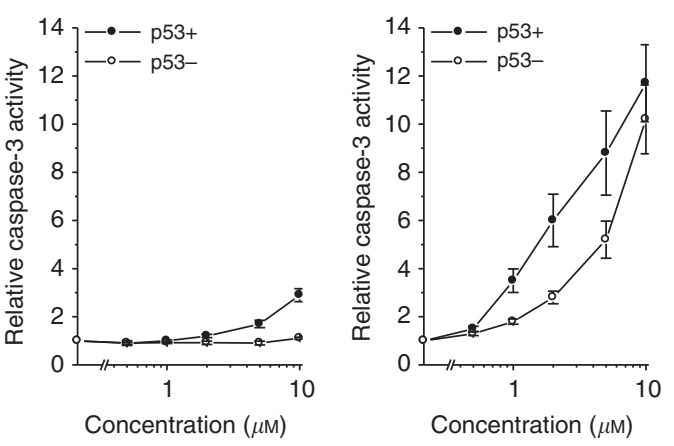

Valproic acid

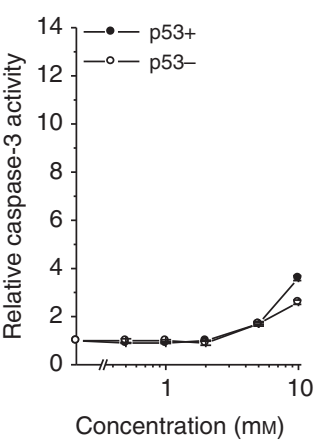

Entinostat
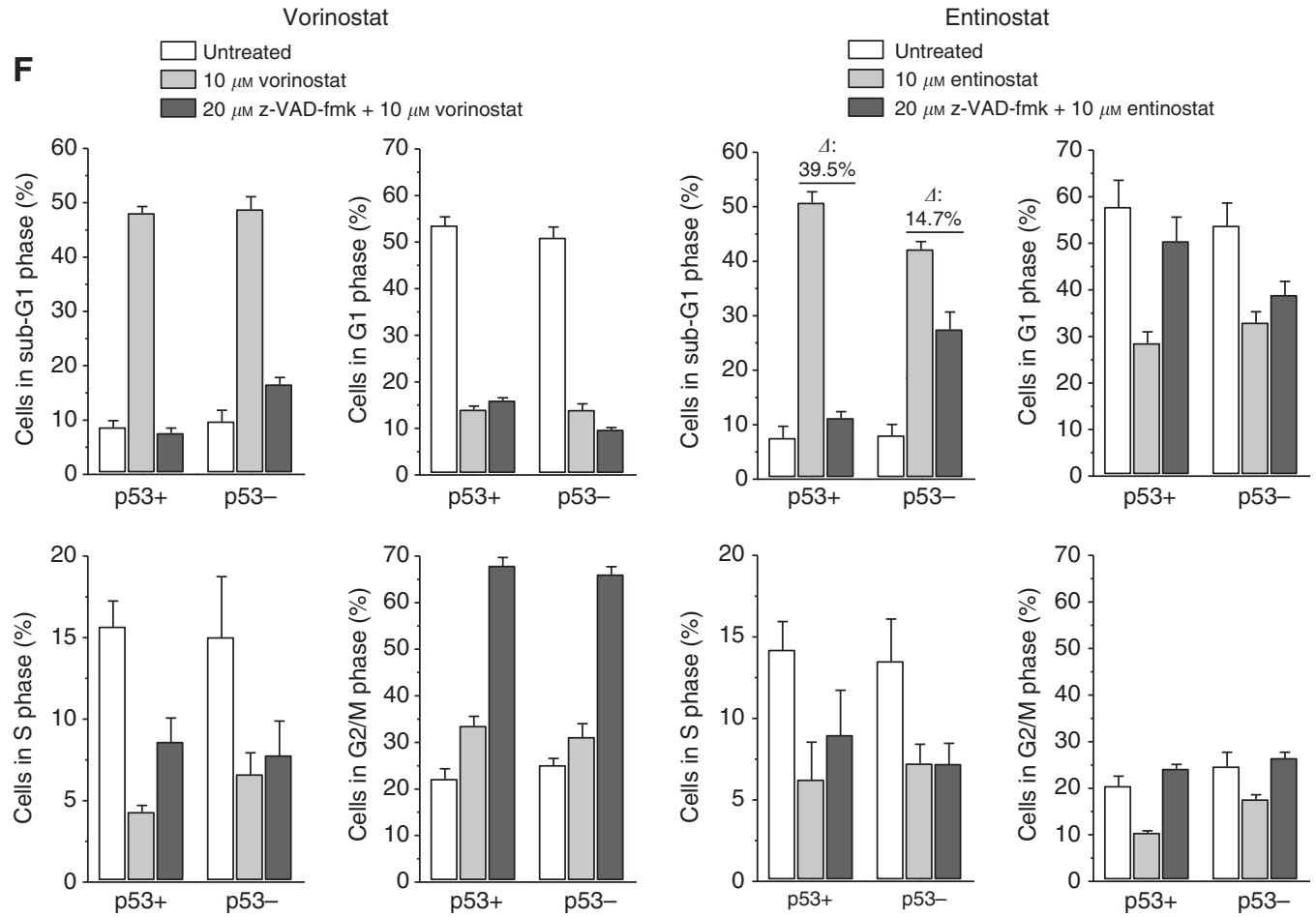

Figure 1. Continued.

but reduced the effects of entinostat to a much lesser degree in p53 - cells (z-VAD-fmk alone had no effect; see Figure 2A and C). Second, we measured caspase- 3 activity. All five agents activated caspase- 3 in p53 + cells, albeit to different extents (Figure 1E). In contrast, entinostat and etoposide had no effect on caspase-3 activity in p53 - cells. Third, we assessed cells for apoptosis by staining the nuclei of ethanol-fixed cells with PI and determining the DNA content by flow cytometry; the sub-G1 fraction of cells with fragmented DNA $<2 n$ is indicative of apoptosis. As demonstrated in Figure 1F, vorinostat- and entinostat-mediated apoptosis amounted to approximately the same level in p53+ and p53 - cells. Yet again, z-VAD-fmk showed different effectiveness dependent on the HDACi applied: it protected cells from vorinostat-triggered apoptosis irrespective of the p53 status, while it was significantly less effective in p53 - cells in preventing entinostat-induced apoptosis. Interestingly, with the inhibition of caspase activity, vorinostat treatment produced a pronounced G2/M arrest-which was largely concealed in the absence of $\mathrm{z}$-VAD-fmk-in both p53 + and p53 - cells (Figure 1F; Supplementary Figure 1).

Antitumour effects of the SIRTi tenovin-1 on HCT-116 p53+ and p53 - cells. So far, our analyses have revealed p53-dependent and -independent effects of different HDACi. Further, we investigated an SIRTi, because the class III HDAC isoforms, the sirtuins, have also recently emerged as promising targets for cancer therapy (Roth and Chen, 2013). An inhibitor of SIRT1 and SIRT2, tenovin-1, has been shown to affect a variety of cancer cell lines in a p53-dependent manner (Lain et al, 2008). To compare tenovin-1 with $\mathrm{HDACi}$, we assessed its effects with the above methods. Figure 2A illustrates that the SIRTi was effective in inducing cell death, $\Delta \psi_{\mathrm{m}}$ dissipation and caspase- 3 activity in $\mathrm{p} 53+$ cells only. Different from its effect on HDACi (see Figure 1D), z-VAD-fmk entirely abolished tenovin-1's cytotoxic action. We further assessed the requirement of p53 for tenovin-1-mediated effects by using the p53 inhibitor pifithrin- $\alpha$ (Komarov et al, 1999): pifithrin- $\alpha$ alleviated tenovin-1-induced-but did not affect vorinostatinduced-cell death, substantiating that the antineoplastic activity of tenovin-1 hinged on p53, whereas that of vorinostat did not (Figure 2B). Cell-cycle analysis confirmed these findings and, moreover, revealed that tenovin-1 produced a G1 cell-cycle arrest in $\mathrm{p} 53+$ cells when apoptosis was blocked by $\mathrm{z}$-VAD-fmk (Figure 2C; Supplementary Figure 2). Hence, the SIRTi tenovin-1 and the HDACi vorinostat exert distinct effects on cell-cycle control in HCT-116 cells.

Effects of HDACi and tenovin-1 on gene expression in HCT-116 p53 + and p53 - cells. The tumour suppressor p53 operates 
A

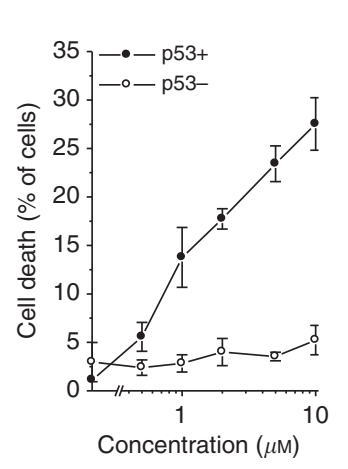

Tenovin-1

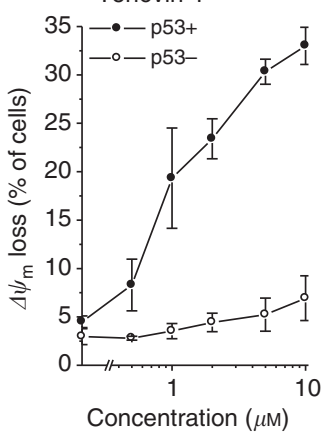

B
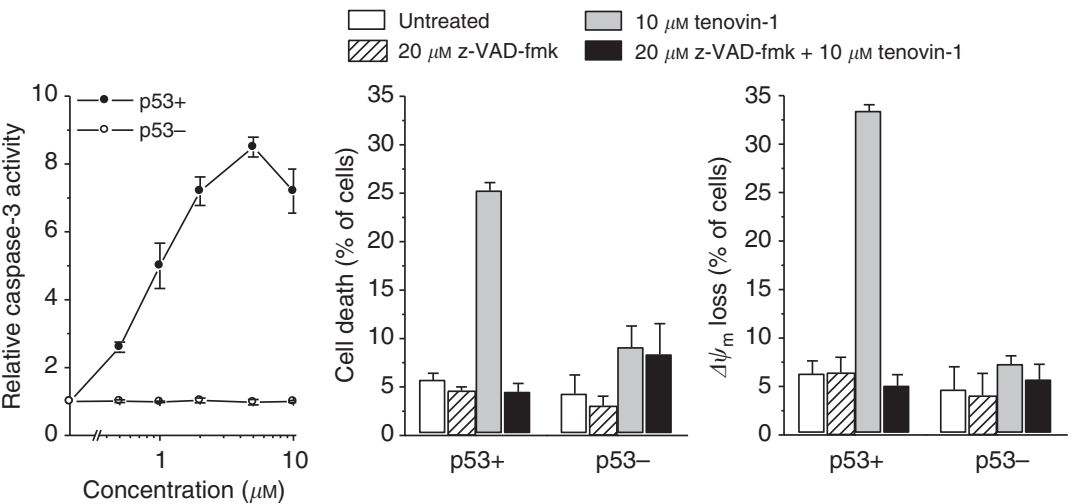

C $\square$ Untreated

$\square 10 \mu \mathrm{m}$ tenovin-1

$20 \mu \mathrm{m}$ z-VAD-fmk + $10 \mu \mathrm{m}$ tenovin- 1

$2 \mu \mathrm{M}$ tenovin-1 - -++-

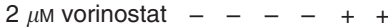

$25 \mu \mathrm{m}$ pifithrin- $\alpha-+-+-+$
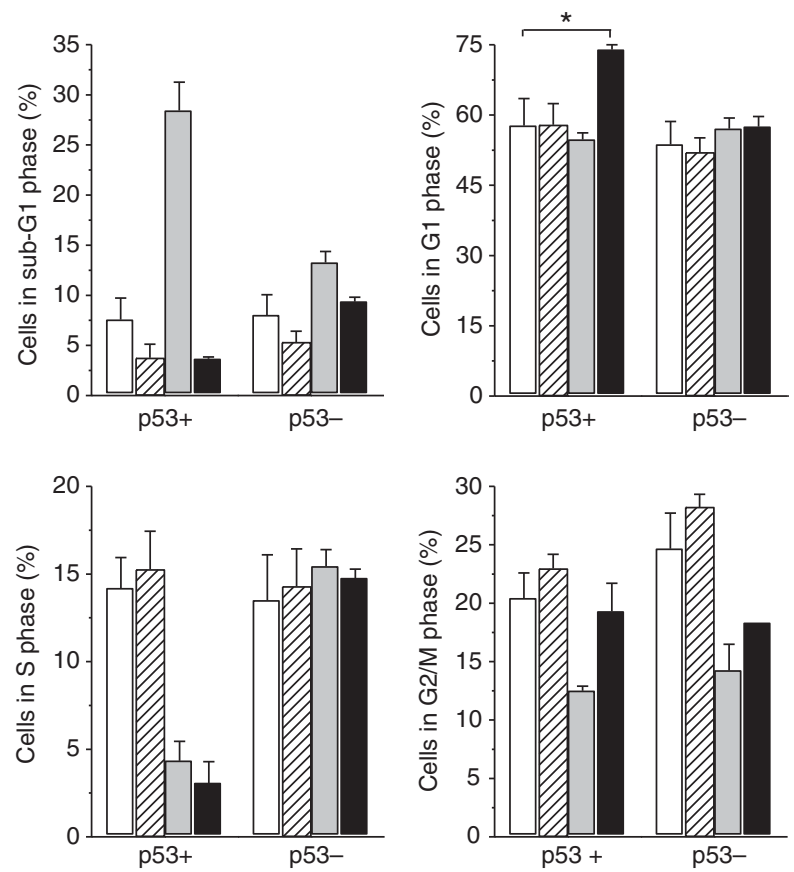

Figure 2. Antineoplastic effects of tenovin-1 in HCT-116 p53 + and p53 - cells. Cells were exposed to tenovin-1 for $24 \mathrm{~h}$ (caspase-3 activity) or $48 \mathrm{~h}$ (other read-outs). z-VAD-fmk was applied $1 \mathrm{~h}$ before treatment with tenovin-1 (A, C). (A) Cell death and $\Delta \psi_{\mathrm{m}}$ were determined by flowcytometric analyses of $\mathrm{PI}$ uptake or $\mathrm{DiOC}_{6}(3)$ staining, respectively; caspase-3 activity was determined using the fluorogenic substrate Ac-DEVDAMC, relative caspase- 3 activities are the ratio of treated cells to untreated cells. (B) Pifithrin- $\alpha$ was applied $1 \mathrm{~h}$ before treatment with tenovin-1 or vorinostat; cell death was determined by flow-cytometric analysis of PI uptake. (C) Cell-cycle profiles were determined by flow cytometry. Means \pm s.e.m. of each three separate measurements are shown. ${ }^{\star} P<0.05 ;{ }^{\star \star} P<0.01$.

predominantly by altering transcriptional programmes, though it can also exert transcription-independent activities (Vousden and Prives, 2009). Likewise, HDACi are supposed to function, at least in part, through their ability to modify gene expression (Bots and Johnstone, 2009; Müller and Krämer, 2010; Spiegel et al, 2012). To investigate a potential interplay of p53 and HDACi at the level of transcription, we determined the mRNA expression levels of p53 itself as well as of MDM2, MDM4 and p21 by real-time RT-PCR. MDM2 and MDM4 (also known as MDMX) are key negative regulators of p53; MDM2 is a transcriptional target of p53 while MDM4 is not (Vousden and Prives, 2009). MDM2 and MDM4 additionally differ in their modes of action: MDM2 primarily acts as an E3 ligase that ubiquitylates p53 for proteasomal degradation, while MDM4 has no ubiquitin ligase activity but acts by inhibiting p53's transactivation function and by seconding MDM2's action (Wade et al, 2013). Figure 3A shows that vorinostat, entinostat and apicidin suppressed the expression of $p 53$, whereas tenovin- 1 and etoposide left it unaffected. MDM2 expression was downregulated by HDACi in p 53 + and p53 - cells, but upregulated by tenovin-1 and etoposide in $\mathrm{p} 53+$ cells. All five agents decreased the expression of MDM4. CDKN1A, the gene encoding the cyclindependent kinase inhibitory protein $\mathrm{p} 21$, is a prominent transcriptional target of p53 (Vousden and Prives, 2009), whose expression can be activated by HDACi independent of p53 (Spiegel et al, 2012) (see also Figure 3B). In contrast, tenovin-1 and etoposide induced CDKN1A expression exclusively in p53 + cells.

To verify the mRNA expression data and to gain more insight into p53-dependent and -independent effects of HDACi and SIRTi, we employed western blot analyses (Figure 3B). Tenovin-1 strongly induced p53 expression, but, strikingly, also vorinostat and entinostat elevated p53 levels. All three agents raised the abundance of acetylated p53. MDM2 levels were decreased by HDACi, but increased by tenovin-1. p21 was induced by HDACi and tenovin- 1 in p53 + cells, but only by HDACi in p53 - cells. Another expression target of p53, the proapoptotic BCL2 family member BAX (Vousden and Prives, 2009), was slightly enhanced 
A $\square$ Control $\square 0.5 \mu \mathrm{M}$ vorinostat
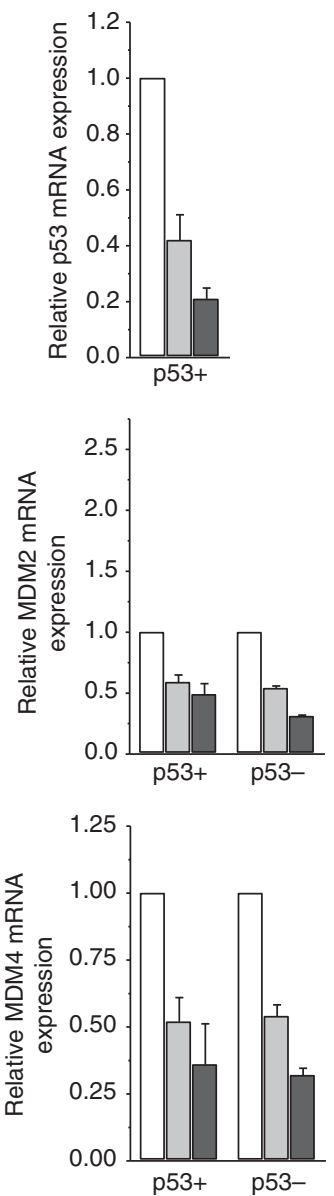

B
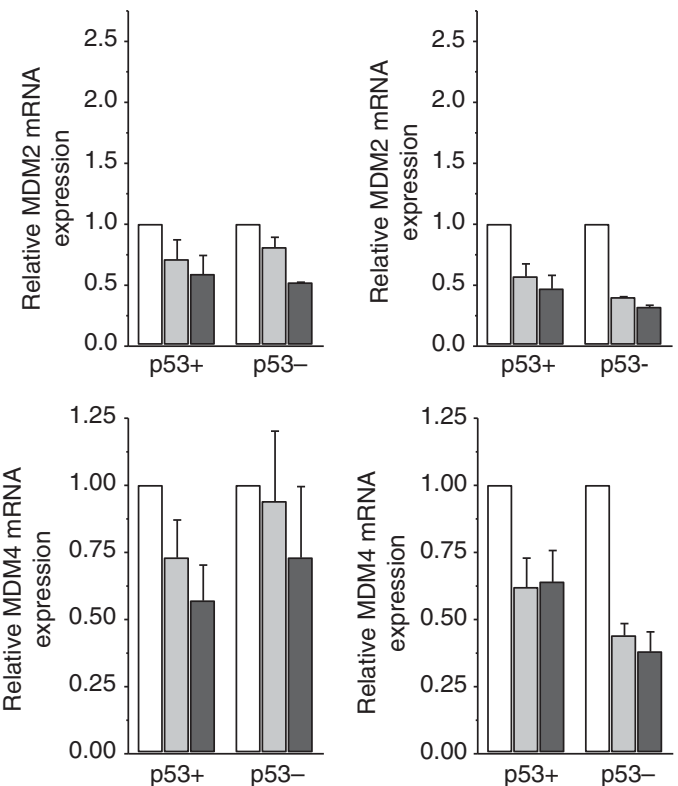

B
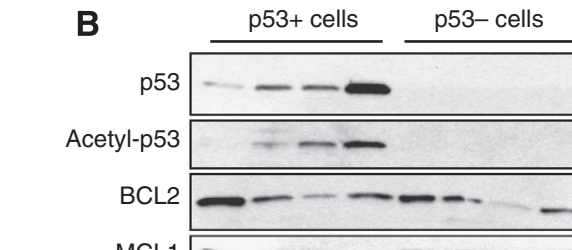

Acetyl-p53

BCL2

$\mathrm{MCL}$
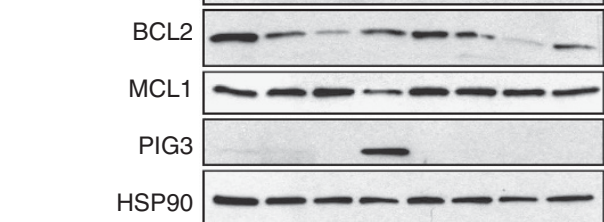

PIG3

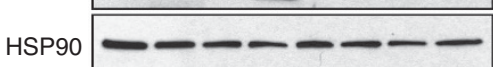

MDM2

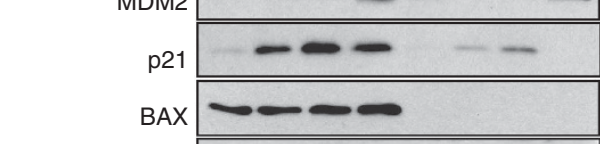

Cleaved PARP-1

Acetyl-H

$\beta$-Actin

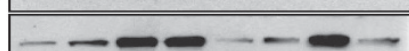

$53+\quad p 53-$
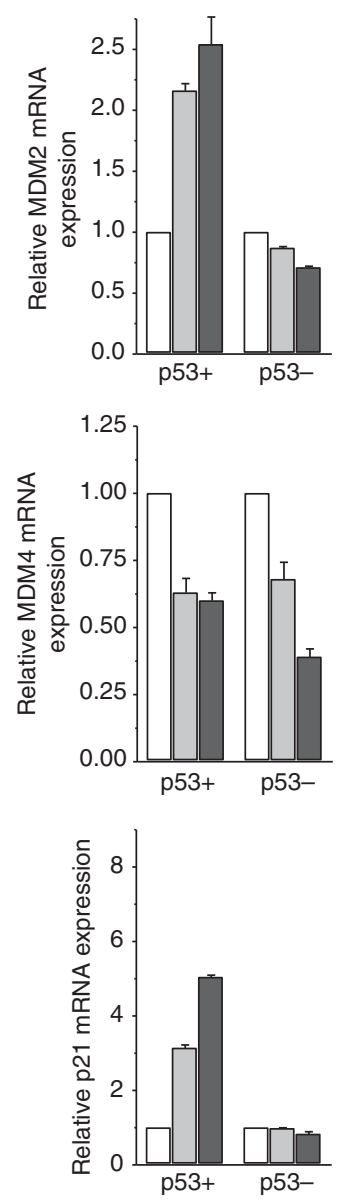
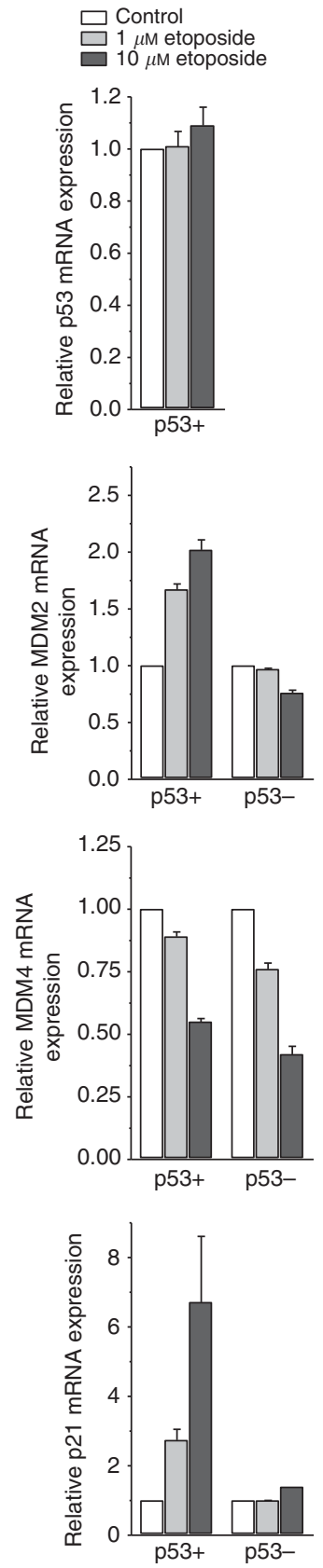

Figure 3. Effects of HDACi and tenovin-1 on gene expression in HCT-116 p53 + and p53 - cells. Cells were exposed to drugs for $24 \mathrm{~h}$. (A) mRNA expression levels were determined by real-time RT-PCR and normalised to $\beta$-2-microglobulin mRNA levels. Means \pm s.e.m. of each two separate measurements are shown. (B) Cells were treated with $2 \mu \mathrm{M} \mathrm{HDACi}$ or $10 \mu \mathrm{m}$ tenovin-1. Protein expression levels were determined by western blotting. 


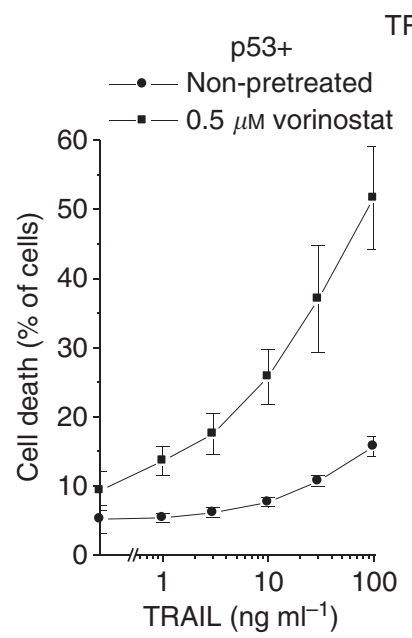

RAIL
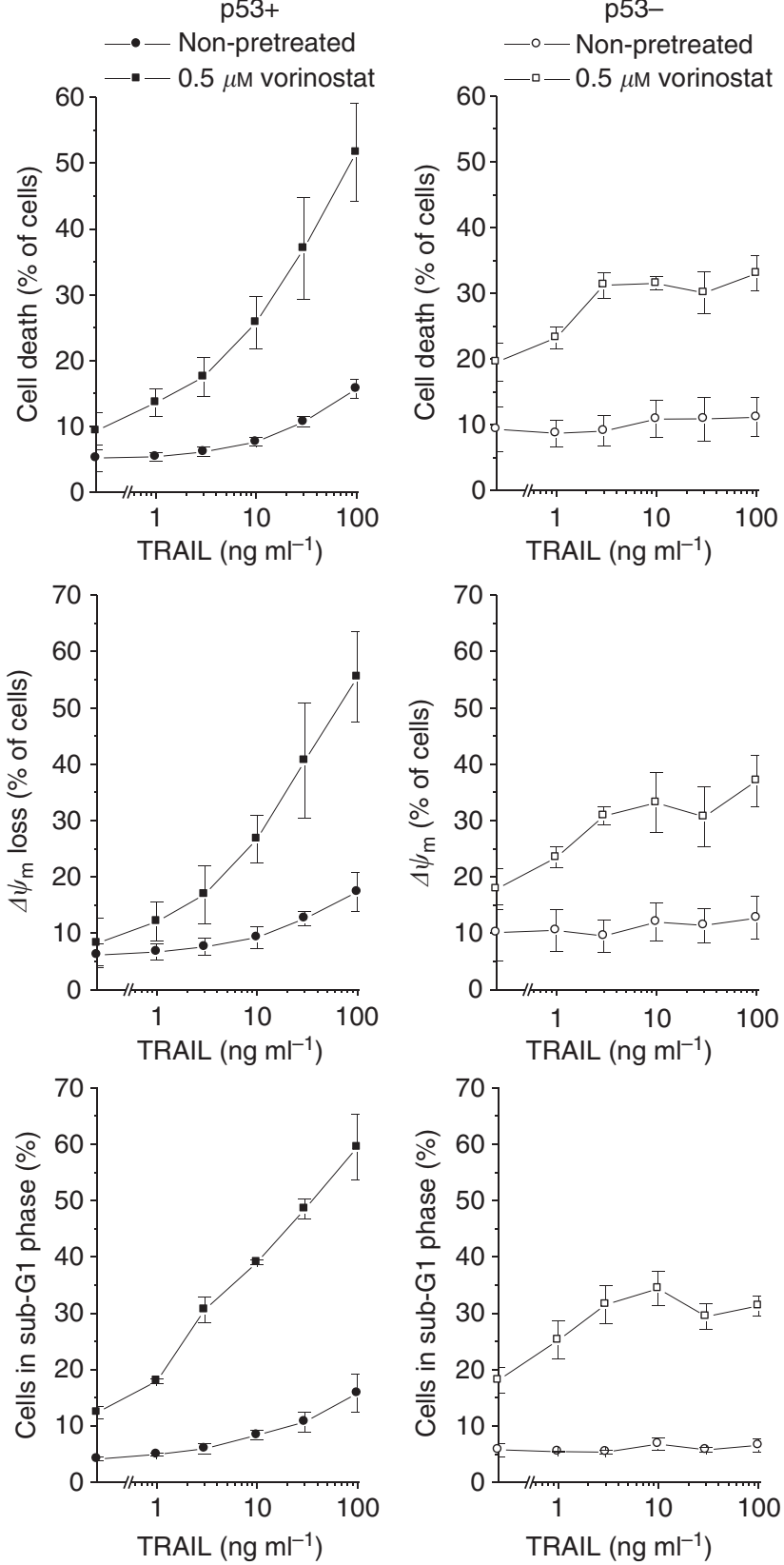

Figure 4. Antineoplastic effects of vorinostat in combination with TRAIL in HCT-116 p53 + and p53 - cells. Four hours after administration of vorinostat, cells were exposed to TRAIL for $48 \mathrm{~h}$. Cell death and $\Delta \psi_{\mathrm{m}}$ were determined by flow-cytometric analyses of $\mathrm{PI}$ uptake or $\mathrm{DiOC}_{6}(3)$ staining, respectively. Cells in sub-G1 phase were determined by flow-cytometric cell-cycle analysis. Means \pm s.e.m. of each three separate measurements are shown.

by tenovin- 1 in p $53+$ cells, but was not detectable in p53 - cells. To elucidate a possible involvement of antiapoptotic proteins whose expression has been demonstrated to be repressed by HDACi (Spiegel et al, 2012), we determined BCL2 and MCL1 levels. BCL2 was downregulated by HDACi and tenovin-1 in a p53-independent manner. Unexpectedly, MCL1 showed a slight trend towards upregulation in $\mathrm{p} 53+$ cells; the densitometric quantification of the corresponding bands (of three independent assessments) revealed that MCL1 was elevated by $37 \%$ (vorinostat), $26 \%$ (entinostat) and 3\% (tenovin-1). In p53 - cells, HDACi caused an insignificant downregulation of MCL1 (vorinostat: $-12 \%$, entinostat: $-13 \%$ ) while tenovin-1 caused a significant one $(-38 \%, P=0.0038)$. Another direct transactivation target of p53, PIG3 (Polyak et al, 1997), was clearly induced by tenovin- 1 in p $53+$ cells only.

In addition, as a further measure for apoptosis, we determined the cleavage of PARP-1 by detecting the $89-\mathrm{kDa}$ cleavage product. Consistent with the other apoptosis read-outs, treatment with HDACi and tenovin-1 provoked the appearance of the PARP-1 fragment in p53 + cells, while only vorinostat caused substantial PARP-1 cleavage in p53 - cells (Figure 3B). To authenticate that HDACi inhibit HDAC activity, we analysed the acetylation status of histone H4. Vorinostat and entinostat induced pronounced histone $\mathrm{H} 4$ hyperacetylation, whereas tenovin-1 did not.

Effects of vorinostat in combination with other anticancer agents in HCT-116 p53 + and p53- cells. The greatest potential of HDACi may lie in their ability to cooperate with other antineoplastic treatment modalities (Bots and Johnstone, 2009; Spiegel et al, 2012). However, the role of p53 in the response of tumour cells to HDACi combination treatments has not yet been resolved.

TRAIL. TRAIL is an attractive candidate for cancer treatment because it targets tumour cells while sparing normal cells. Yet, many tumours fail to respond to TRAIL monotherapy and, thus, require cotreatment with sensitising agents in order for TRAIL to exert antineoplastic activity (Ashkenazi, 2008). Histone deacetylase inhibitors have been established as potent TRAIL sensitisers (Bots and Johnstone, 2009; Spiegel et al, 2012). Cell killing by TRAIL does in general not depend on p53, but on BAX (Deng et al, 2002; LeBlanc et al, 2002). Because HCT-116 p53cells did not express BAX (see Figure 3B), these cells were likely to be resistant to TRAIL. Indeed, p53 - cells showed no response to TRAIL, as judged by determining cell death, $\Delta \psi_{\mathrm{m}}$ loss and DNA fragmentation (Figure 4). However, vorinostat sensitised both p53 + and p53 - cells to TRAIL-induced apoptosis, though the sensitising effect was less pronounced in the latter.

Proteasome inhibitor bortezomib. Histone deacetylase inhibitors synergise with proteasome inhibitors, such as bortezomib, and phase II and phase III clinical trials of vorinostat in combination with bortezomib have been initiated (Bots and Johnstone, 2009). As with HDACi, the role of p53 in the response of cancer cells to bortezomib is controversial. For instance, in HCT-116 cells, bortezomib-induced apoptosis has been reported to both depend and not depend on p53 (Ding et al, 2007; Pandit and Gartel, 2011). Here, we explored whether the vorinostat/bortezomib combination effect depended on p53 by determining cell death and $\Delta \psi_{\mathrm{m}}$ loss. Figure 5A shows that bortezomib elicited a concentrationdependent effect in p53 + and p53 - cells, which was, however, weaker in the latter. Vorinostat enhanced bortezomib-induced cell death and $\Delta \psi_{\mathrm{m}}$ dissipation irrespective of the cells' p53 status.

$N F-\kappa B$ inhibitor CAPE. Bortezomib is an inhibitor of the transcription factor NF- $\kappa \mathrm{B}$, which can induce a number of tumour-promoting effects. It is unclear to which extent bortezomib's antineoplastic effects stem from suppression of NF- $\kappa \mathrm{B}$ activity (Chaturvedi et al, 2011). Therefore, we tested whether the observed cooperative action of vorinostat and bortezomib could be mimicked by the combination of vorinostat with the NF- $\kappa \mathrm{B}$ inhibitor CAPE (Schneider and Krämer, 2011). As presented in Figure $5 \mathrm{~B}$, the combination of vorinostat and CAPE was equally effective in p53 + and p53 - cells.

Obatoclax. Histone deacetylase inhibitors have been shown to reduce the expression of the antiapoptotic BCL2 family member MCL1 (Spiegel et al, 2012). To our surprise, we found that vorinostat and entinostat somewhat, albeit insignificantly, 
A
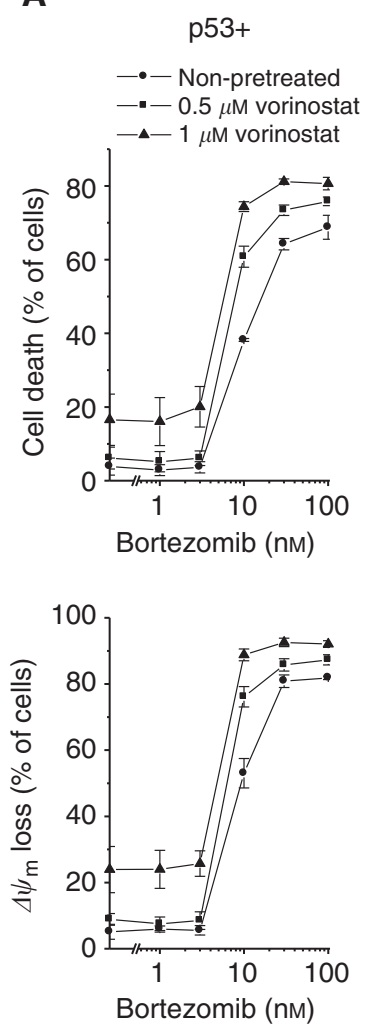

p53-
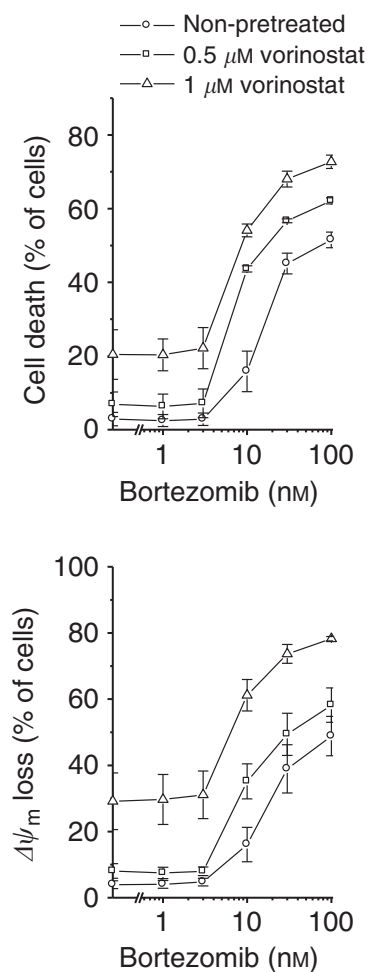

B
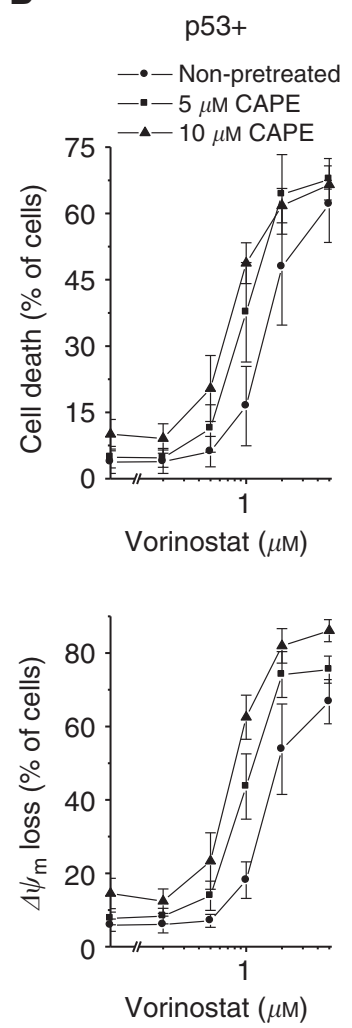

CAPE
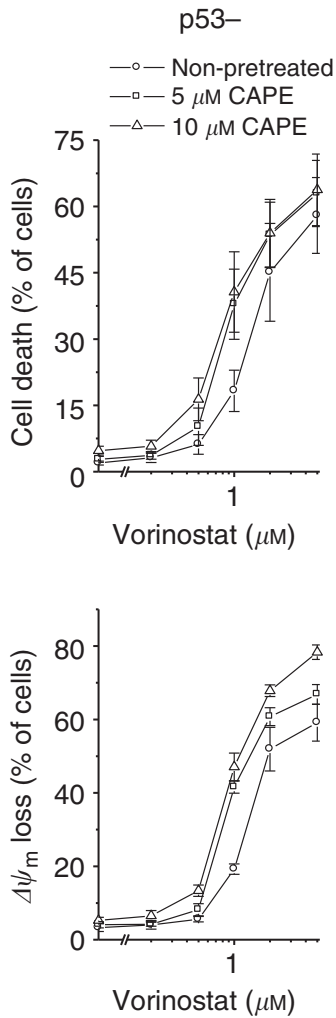

Figure 5. Antineoplastic effects of vorinostat in combination with bortezomib or CAPE in HCT-116 p53 + and p53 - cells. (A) Four hours after administration of vorinostat, cells were exposed to bortezomib for $48 \mathrm{~h}$. (B) One hour after administration of CAPE, cells were exposed to vorinostat for $48 \mathrm{~h}$. Cell death and $\Delta \psi_{\mathrm{m}}$ were determined by flow-cytometric analyses of PI uptake or $\mathrm{DiOC}_{6}(3)$ staining, respectively. Means \pm s.e.m. of each three separate measurements are shown.

increased MCL1 levels in p53 + cells (see Figure 3B). Hence, by inducing MCL1, HDACi could potentially, by themselves, limit their efficacy. If this was the case, then inhibition of MCL1 should enhance the anticancer action of HDACi. To test this hypothesis, we applied the MCL1 inhibitor obatoclax (Nguyen et al, 2007). Figure 6 shows that vorinostat was similarly effective in the presence and in the absence of obatoclax, suggesting that MCL1 is not crucial for HDACi-induced anticancer effects.

\section{DISCUSSION}

In this study, we delineated p53-dependent and -independent activities of HDACi and, in part, resolved the controversies (Vrana et al, 1999; Huang et al, 2000; Ruefli et al, 2001; Yu et al, 2002; Henderson et al, 2003; Insinga et al, 2005; Joseph et al, 2005; Kim et al, 2006; Sonnemann et al, 2006; Lindemann et al, 2007; Condorelli et al, 2008; Ellis et al, 2009; Hacker et al, 2011; Bajbouj et al, 2012; Meng et al, 2012) over the impact of p53 on HDACidriven effects. As general bottom line, we have shown that HDACi accomplish the ultimate goal of cancer therapy, the demise of malignant cells, independent of the tumour's p53 status. In addition, a number of distinctive features regarding the molecular effects of HDACi-and SIRTi-emerged from our study.

We noted that p53 was of variable significance for the biological effects of different HDACi: vorinostat, apicidin and VPA were practically as effective in p53- as in p53 + cells, whereas entinostat was less effective in the former. This finding suggests that HDACi with narrower specificity are more likely to depend on functional p53 (see Supplementary Table 1). It also suggests that the inconsistencies in previous studies stemmed from the particular HDACi investigated, though it is also possible that p53 is of different relevance in different model systems. Interestingly, vorinostat and entinostat differed in another respect: only vorinostat elicited a strong G2/M arrest when cells were protected from apoptosis by the pan-caspase inhibitor z-VAD-fmk (in both p53 + and p53 - cells). Hence, vorinostat is capable of provoking growth arrest when its apoptosis-promoting activity is blocked. Taken together, these observations demonstrate that vorinostat can exert anticancer activities in the absence of both, functional p53 and intact caspases, in line with previous findings (Ellis et al, 2009).

As to caspases, it is worth noting that all four HDACi induced lesser caspase- 3 activation in p53 - cells, which, however, in case of vorinostat, apicidin and VPA, was not accompanied by lesser cell death. This finding shows that HDACi-triggered caspase activity does hinge, to some extent, on p53, though cell killing by vorinostat, apicidin and VPA does not. Therefore, studies that rest predominantly on the analysis of caspase activation may be misleading with regard to relevance of p53 for the antineoplastic action of HDACi. In this context, it should also be noted that $\mathrm{z}$-VAD-fmk protected cells only incompletely from cell death, pointing to a caspase-independent mechanism of cell death induced by vorinostat and entinostat. Strikingly, the partially p53-dependent agent entinostat was more susceptible than vorinostat to inhibition by $\mathrm{z}-\mathrm{VAD}-\mathrm{fmk}$ in $\mathrm{p} 53+$ cells. On the other hand, in p53 - cells, entinostat was much less prevented by $\mathrm{z}$-VAD-fmk from mediating cell death and, consistently, failed to induce detectable caspase-3 activity and substantial PARP-1 cleavage. From these observations, it can be concluded that entinostat promotes mainly caspase-dependent cell death in p53+ cells, whereas, in p53 - cells, caspase inhibition switches the mode 


\section{Obatoclax}
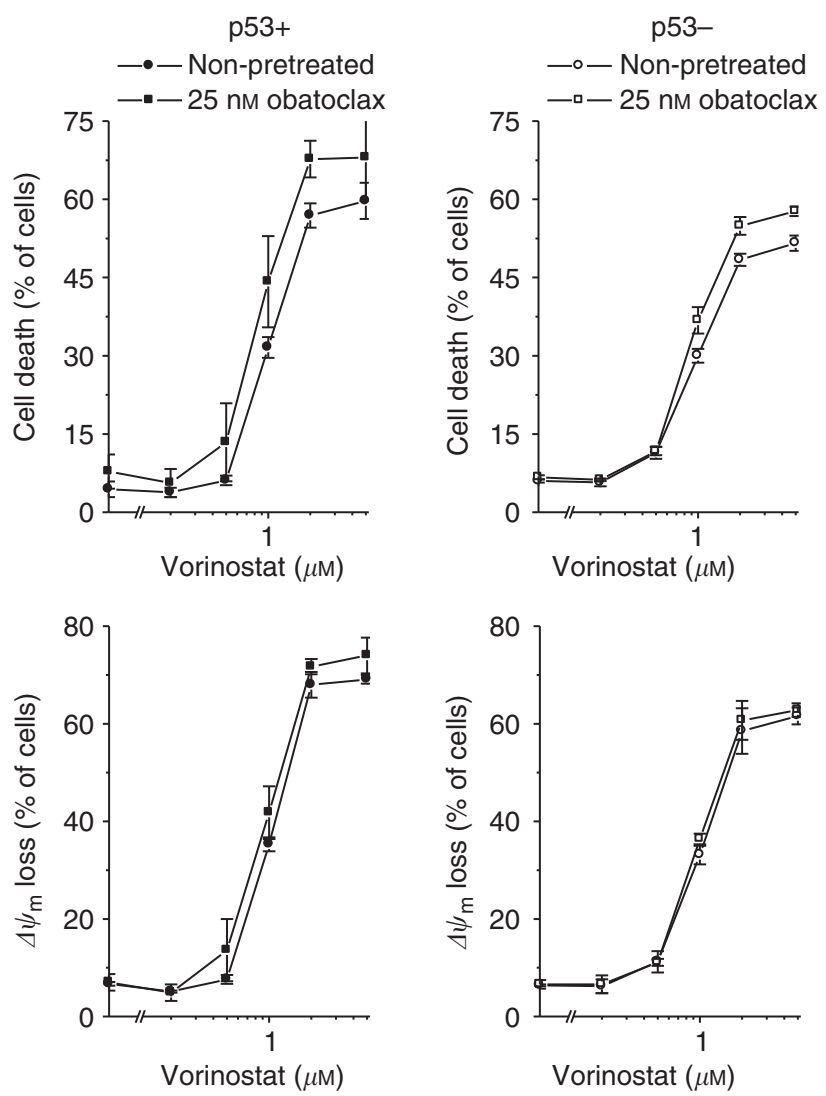

Figure 6. Antineoplastic effects of vorinostat in combination with obatoclax in HCT-116 p53 + and p53 - cells. One hour after administration of obatoclax, cells were exposed to vorinostat for $48 \mathrm{~h}$. Cell death and $\Delta \psi_{\mathrm{m}}$ were determined by flow-cytometric analyses of $\mathrm{PI}$ uptake or $\mathrm{DiOC}_{6}(3)$ staining, respectively. Means \pm s.e.m. of each three separate measurements are shown.

of cell death to a mainly non-caspase-dependent one. It can also be concluded that the p53-dependent fraction of cell death is particularly sensitive to caspase inhibition.

The latter consideration is also in line with the finding that cell death induced by the SIRTi tenovin-1 depended on p53 and could be blocked by $\mathrm{z}$-VAD-fmk. The seven sirtuins are presently emerging as promising drug targets for various diseases, yet they appear to have ambiguous roles in cancerogenesis (Roth and Chen, 2013). In particular SIRT1, the most widely studied sirtuin isoform, may operate as either tumour promoter or tumour suppressor: on the one hand, SIRT1 can repress p53 function via deacetylation, on the other hand, it can also facilitate DNA repair (Fang and Nicholl, 2011). Here, we have shown that tenovin-1 acted antineoplastically against HCT-116 p53 + cells. We found that tenovin-1 elicited cell death, in keeping with the study that discovered tenovins as potential antitumour agents (Lain et al, 2008). Furthermore, we found that tenovin-1 caused a G1 cell-cycle arrest when cell death was prevented by z-VAD-fmk, a feature that has not been previously described. Our protein expression analysis demonstrated that tenovin-1 strongly elevated the abundance of p53 and acetylated p53 and induced three key targets of p53, that is, MDM2, p21 and PIG3, in p53 + cells. The observation that tenovin- 1 treatment simultaneously increased p53, acetylated p53 and the intrinsic p53 inhibitor MDM2 (mRNA and protein) points to the following scenario: MDM2 is induced by p53 activation in a feedback loop that normally serves to negatively control p53 activity (Vousden and Prives, 2009). However, MDM2 interacts only weakly with acetylated p53 and thus inefficiently destabilises p53 (Poyurovsky et al, 2010). All told, our data indicate that tenovin-1 exerts anticancer effects via p53. Yet, we also found that tenovin-1 diminished BCL2 expression in p53 + and p53cells, showing that tenovin-1 can act on gene expression in a p53independent manner, though its cell-killing action had the requirement for $\mathrm{p} 53$.

The PCR and western blotting analyses confirm the notion that HDACi can modulate gene expression in a p53-independent manner. For instance, HDACi reduced the expression of the antiapoptotic protein BCL2 independently of the cellular p53 status. Likewise, in consistence with previous reports (Spiegel et al, 2012), vorinostat and entinostat upregulated p21, a major transcriptional target of p53 (Vousden and Prives, 2009), in $\mathrm{p} 53+$ and $\mathrm{p} 53$ - cells. It should be taken into account, however, that the induction of p21 was less pronounced in p53cells, in accordance with data collected in a study on lung cancer cells (Zhao et al, 2006). In contrast, the p21-inducing activity of tenovin- 1 and etoposide was restricted to p53+ cells. More interestingly, we observed a considerable effect of HDACi on the expression of p53 itself and of the two p53 negative regulators, MDM2 and MDM4. At the transcriptional level, vorinostat, entinostat and apicidin downregulated the expression of $p 53$, MDM2 and MDM4. It is of note that MDM2 downregulation also occurred in p53 - cells, evidencing that this effect was not the consequence of $\mathrm{p} 53$ downregulation. At the protein level, vorinostat and entinostat blocked MDM2 expression, but induced p53. The implication is therefore that the downregulation of MDM2 overrides the downregulation of p53 mRNA, and the net result of these opposing effects is the increase in p53 abundance. We have previously observed that HDACi suppress MDM2 expression also in other cancer cell lines (Brandl et al, 2012; Palani et al, 2012), suggesting that this is a general effect of HDACi. Hence, HDACi can activate p53 by attenuating MDM2. In addition, it is equally possible that HDACi- and SIRTi-mediated acetylation of $\mathrm{p} 53$ weakens the p53-MDM2 interaction, that way stabilising p53 (Zhao et al, 2006; Poyurovsky et al, 2010; Brandl et al, 2012; Gu and Zhu, 2012). This consideration appears to particularly apply to tenovin-1 treatment, which increased the abundance of both p53 and MDM2. At the level of transcription, tenovin-1 had no effect on $p 53$ expression, whereas vorinostat, entinostat and apicidin suppressed it. These observations suggest that class I HDACs are necessary for expression of the p53 gene. Further studies are underway to address the interplay of HDAC activity, p53 acetylation and MDM2 expression in the control of p53 expression. To sum up this point, HDACi can activate p53, but they do not necessarily require p53 for inhibiting cancer cell growth and survival.

Likewise, vorinostat does not require p53 to enhance the anticancer action of other agents, at least with regard to the agents tested in this study. Vorinostat cooperated with the apoptosisinducing cytokine TRAIL, the proteasome inhibitor bortezomib and the NF- $\kappa$ B inhibitor CAPE, in killing both p $53+$ and p53cells. Notably, vorinostat enhanced the cytotoxic activity of bortezomib equally effective in p53 - cells, which were less responsive to bortezomib alone, and it sensitised p53 - cells to TRAIL-mediated cell death. TRAIL is generally conceived to elicit cell death independent of p53 (Ashkenazi, 2008). Yet we found p53 - cells to be resistant to TRAIL, which is most likely attributable to the lack of BAX expression in these cells (see Figure 3B). Indeed, BAX-deficient HCT-116 cells have been shown to be unresponsive to TRAIL-induced apoptosis (Deng et al, 2002; LeBlanc et al, 2002). Our data suggest that vorinostat treatment partially overcame this type of resistance.

In summary, the present study substantiates the general usefulness of HDACi-applied as single agents or in conjunction 
with other antineoplastic regimens-for the treatment of p53-deficient tumours. Yet it also demonstrates that the action of some HDACi may be partially influenced by p53. Thus, p53 independence of HDACi cannot a priori be taken for granted. Furthermore, it shows that HDACi suppress MDM2 expression and induce accumulation of $\mathrm{p} 53$, a feature that might have confounded conclusions on the relevance of p53 for HDACimediated anticancer effects in previous studies on this subject.

\section{ACKNOWLEDGEMENTS}

We thank Dr Bert Vogelstein for HCT-116 cells and Dr Christian Wichmann for obatoclax. CM is supported by the DFG RTG 1715.

\section{CONFLICT OF INTEREST}

There authors declare no conflict of interest.

\section{REFERENCES}

Aas T, Borresen AL, Geisler S, Smith-Sorensen B, Johnsen H, Varhaug JE, Akslen LA, Lonning PE (1996) Specific P53 mutations are associated with de novo resistance to doxorubicin in breast cancer patients. Nat Med 2: 811-814.

Arrowsmith CH, Bountra C, Fish PV, Lee K, Schapira M (2012) Epigenetic protein families: a new frontier for drug discovery. Nat Rev Drug Discov 11: 384-400.

Ashkenazi A (2008) Directing cancer cells to self-destruct with pro-apoptotic receptor agonists. Nat Rev Drug Discov 7: 1001-1012.

Bajbouj K, Mawrin C, Hartig R, Schulze-Luehrmann J, Wilisch-Neumann A, Roessner A, Schneider-Stock R (2012) P53-dependent antiproliferative and pro-apoptotic effects of trichostatin A (TSA) in glioblastoma cells. J Neurooncol 107: 503-516.

Baylin SB, Jones PA (2011) A decade of exploring the cancer epigenomebiological and translational implications. Nat Rev Cancer 11: 726-734.

Bots M, Johnstone RW (2009) Rational combinations using HDAC inhibitors. Clin Cancer Res 15: 3970-3977.

Bradner JE, West N, Grachan ML, Greenberg EF, Haggarty SJ, Warnow T, Mazitschek R (2010) Chemical phylogenetics of histone deacetylases. Nat Chem Biol 6: 238-243.

Brandl A, Wagner T, Uhlig KM, Knauer SK, Stauber RH, Melchior F, Schneider G, Heinzel T, Krämer OH (2012) Dynamically regulated sumoylation of HDAC2 controls p53 deacetylation and restricts apoptosis following genotoxic stress. J Mol Cell Biol 4: 284-293.

Buchwald M, Krämer OH, Heinzel T (2009) HDACi-targets beyond chromatin. Cancer Lett 280: 160-167.

Bunz F, Dutriaux A, Lengauer C, Waldman T, Zhou S, Brown JP, Sedivy JM, Kinzler KW, Vogelstein B (1998) Requirement for p53 and p21 to sustain G2 arrest after DNA damage. Science 282: 1497-1501.

Chaturvedi MM, Sung B, Yadav VR, Kannappan R, Aggarwal BB (2011) NF-kappaB addiction and its role in cancer: 'one size does not fit all'. Oncogene 30: 1615-1630.

Chipuk JE, Green DR (2005) Do inducers of apoptosis trigger caspaseindependent cell death? Nat Rev Mol Cell Biol 6: 268-275.

Condorelli F, Gnemmi I, Vallario A, Genazzani AA, Canonico PL (2008) Inhibitors of histone deacetylase (HDAC) restore the p53 pathway in neuroblastoma cells. Br J Pharmacol 153: 657-668.

Deng Y, Lin Y, Wu X (2002) TRAIL-induced apoptosis requires Baxdependent mitochondrial release of Smac/DIABLO. Genes Dev 16: 33-45.

Ding WX, Ni HM, Chen X, Yu J, Zhang L, Yin XM (2007) A coordinated action of Bax, PUMA, and p53 promotes MG132-induced mitochondria activation and apoptosis in colon cancer cells. Mol Cancer Ther 6: 1062-1069.

Ellis L, Bots M, Lindemann RK, Bolden JE, Newbold A, Cluse LA, Scott CL, Strasser A, Atadja P, Lowe SW, Johnstone RW (2009) The histone deacetylase inhibitors LAQ824 and LBH589 do not require death receptor signaling or a functional apoptosome to mediate tumor cell death or therapeutic efficacy. Blood 114: 380-393.
Fang Y, Nicholl MB (2011) Sirtuin 1 in malignant transformation: friend or foe? Cancer Lett 306: 10-14.

Gu B, Zhu WG (2012) Surf the post-translational modification network of p53 regulation. Int J Biol Sci 8: 672-684.

Hacker S, Karl S, Mader I, Cristofanon S, Schweitzer T, Krauss J, Rutkowski S, Debatin KM, Fulda S (2011) Histone deacetylase inhibitors prime medulloblastoma cells for chemotherapy-induced apoptosis by enhancing p53-dependent Bax activation. Oncogene 30: 2275-2281.

Henderson C, Mizzau M, Paroni G, Maestro R, Schneider C, Brancolini C (2003) Role of caspases, Bid, and p53 in the apoptotic response triggered by histone deacetylase inhibitors trichostatin-A (TSA) and suberoylanilide hydroxamic acid (SAHA). J Biol Chem 278: 12579-12589.

Huang L, Sowa Y, Sakai T, Pardee AB (2000) Activation of the p21WAF1/ CIP1 promoter independent of $\mathrm{p} 53$ by the histone deacetylase inhibitor suberoylanilide hydroxamic acid (SAHA) through the Sp1 sites. Oncogene 19: $5712-5719$.

Insinga A, Monestiroli S, Ronzoni S, Gelmetti V, Marchesi F, Viale A, Altucci L, Nervi C, Minucci S, Pelicci PG (2005) Inhibitors of histone deacetylases induce tumor-selective apoptosis through activation of the death receptor pathway. Nat Med 11: 71-76.

Joseph J, Wajapeyee N, Somasundaram K (2005) Role of p53 status in chemosensitivity determination of cancer cells against histone deacetylase inhibitor sodium butyrate. Int J Cancer 115: 11-18.

Kim IA, Shin JH, Kim IH, Kim JH, Kim JS, Wu HG, Chie EK, Ha SW, Park CI, Kao GD (2006) Histone deacetylase inhibitor-mediated radiosensitization of human cancer cells: class differences and the potential influence of p53. Clin Cancer Res 12: 940-949.

Komarov PG, Komarova EA, Kondratov RV, Christov-Tselkov K, Coon JS, Chernov MV, Gudkov AV (1999) A chemical inhibitor of p53 that protects mice from the side effects of cancer therapy. Science 285: 1733-1737.

Lain S, Hollick JJ, Campbell J, Staples OD, Higgins M, Aoubala M, McCarthy A, Appleyard V, Murray KE, Baker L, Thompson A, Mathers J, Holland SJ, Stark MJ, Pass G, Woods J, Lane DP, Westwood NJ (2008) Discovery, in vivo activity, and mechanism of action of a small-molecule p53 activator. Cancer Cell 13: 454-463.

LeBlanc H, Lawrence D, Varfolomeev E, Totpal K, Morlan J, Schow P, Fong S, Schwall R, Sinicropi D, Ashkenazi A (2002) Tumor-cell resistance to death receptor-induced apoptosis through mutational inactivation of the proapoptotic Bcl-2 homolog Bax. Nat Med 8: 274-281.

Lindemann RK, Newbold A, Whitecross KF, Cluse LA, Frew AJ, Ellis L, Williams S, Wiegmans AP, Dear AE, Scott CL, Pellegrini M, Wei A, Richon VM, Marks PA, Lowe SW, Smyth MJ, Johnstone RW (2007) Analysis of the apoptotic and therapeutic activities of histone deacetylase inhibitors by using a mouse model of B cell lymphoma. Proc Natl Acad Sci USA 104: 8071-8076.

Lowe SW, Ruley HE, Jacks T, Housman DE (1993) p53-dependent apoptosis modulates the cytotoxicity of anticancer agents. Cell $\mathbf{7 4}$ 957-967.

Meng J, Zhang HH, Zhou CX, Li C, Zhang F, Mei QB (2012) The histone deacetylase inhibitor trichostatin A induces cell cycle arrest and apoptosis in colorectal cancer cells via p53-dependent and -independent pathways. Oncol Rep 28: 384-388.

Müller S, Krämer OH (2010) Inhibitors of HDACs-effective drugs against cancer? Curr Cancer Drug Targets 10: 210-228.

Nguyen M, Marcellus RC, Roulston A, Watson M, Serfass L, Murthy Sr. M, Goulet D, Viallet J, Belec L, Billot X, Acoca S, Purisima E, Wiegmans A, Cluse L, Johnstone RW, Beauparlant P, Shore GC (2007) Small molecule obatoclax (GX15-070) antagonizes MCL-1 and overcomes MCL-1-mediated resistance to apoptosis. Proc Natl Acad Sci USA 104: 19512-19517.

O’Connor PM, Jackman J, Bae I, Myers TG, Fan S, Mutoh M, Scudiero DA, Monks A, Sausville EA, Weinstein JN, Friend S, Fornace Jr AJ, Kohn KW (1997) Characterization of the p53 tumor suppressor pathway in cell lines of the National Cancer Institute anticancer drug screen and correlations with the growth-inhibitory potency of 123 anticancer agents. Cancer Res 57: 4285-4300.

Palani CD, Beck JF, Sonnemann J (2012) Histone deacetylase inhibitors enhance the anticancer activity of nutlin-3 and induce p53 hyperacetylation and downregulation of MDM2 and MDM4 gene expression. Invest New Drugs 30: 25-36.

Pandit B, Gartel AL (2011) Proteasome inhibitors induce p53-independent apoptosis in human cancer cells. Am J Pathol 178: 355-360. 
Polyak K, Xia Y, Zweier JL, Kinzler KW, Vogelstein B (1997) A model for p53-induced apoptosis. Nature 389: 300-305.

Poyurovsky MV, Katz C, Laptenko O, Beckerman R, Lokshin M, Ahn J, Byeon IJ, Gabizon R, Mattia M, Zupnick A, Brown LM, Friedler A, Prives C (2010) The C terminus of p53 binds the N-terminal domain of MDM2. Nat Struct Mol Biol 17: 982-989.

Roth M, Chen WY (2013) Sorting out functions of sirtuins in cancer. Oncogene; e-pub ahead of print 22 April 2013; doi:10.1038/onc.2013.120.

Ruefli AA, Ausserlechner MJ, Bernhard D, Sutton VR, Tainton KM, Kofler R, Smyth MJ, Johnstone RW (2001) The histone deacetylase inhibitor and chemotherapeutic agent suberoylanilide hydroxamic acid (SAHA) induces a cell-death pathway characterized by cleavage of Bid and production of reactive oxygen species. Proc Natl Acad Sci USA 98: 10833-10838.

Schneider G, Krämer OH (2011) NFkappaB/p53 crosstalk-a promising new therapeutic target. Biochim Biophys Acta 1815: 90-103.

Sonnemann J, Hartwig M, Plath A, Saravana KK, Müller C, Beck JF (2006) Histone deacetylase inhibitors require caspase activity to induce apoptosis in lung and prostate carcinoma cells. Cancer Lett 232: 148-160.

Soussi T, Beroud C (2001) Assessing TP53 status in human tumours to evaluate clinical outcome. Nat Rev Cancer 1: 233-240.

Spiegel S, Milstien S, Grant S (2012) Endogenous modulators and pharmacological inhibitors of histone deacetylases in cancer therapy. Oncogene 31: 537-551.
Vousden KH, Prives C (2009) Blinded by the light: the growing complexity of p53. Cell 137: 413-431.

Vrana JA, Decker RH, Johnson CR, Wang Z, Jarvis WD, Richon VM, Ehinger M, Fisher PB, Grant S (1999) Induction of apoptosis in U937 human leukemia cells by suberoylanilide hydroxamic acid (SAHA) proceeds through pathways that are regulated by $\mathrm{Bcl}-2 / \mathrm{Bcl}-\mathrm{XL}, \mathrm{c}-J u n$, and p21CIP1, but independent of p53. Oncogene 18: 7016-7025.

Wade M, Li YC, Wahl GM (2013) MDM2, MDMX and p53 in oncogenesis and cancer therapy. Nat Rev Cancer 13: 83-96.

Yu X, Guo ZS, Marcu MG, Neckers L, Nguyen DM, Chen GA, Schrump DS (2002) Modulation of p53, ErbB1, ErbB2, and Raf-1 expression in lung cancer cells by depsipeptide FR901228. J Natl Cancer Inst 94: 504-513.

Zhao Y, Lu S, Wu L, Chai G, Wang H, Chen Y, Sun J, Yu Y, Zhou W, Zheng Q, Wu M, Otterson GA, Zhu WG (2006) Acetylation of p53 at lysine $373 / 382$ by the histone deacetylase inhibitor depsipeptide induces expression of p21(Waf1/Cip1). Mol Cell Biol 26: 2782-2790.

This work is published under the standard license to publish agreement. After 12 months the work will become freely available and the license terms will switch to a Creative Commons AttributionNonCommercial-Share Alike 3.0 Unported License.

Supplementary Information accompanies this paper on British Journal of Cancer website (http://www.nature.com/bjc) 